\title{
Uncertainty analysis of thermal conductivity measurements in materials for energy-efficient buildings
}

\author{
L. $\operatorname{Laghi}^{1, \star}$, F. Pennecchi ${ }^{2}$, and G. Raiteri ${ }^{3}$ \\ 1 CertiMaC ScarL, Via Granarolo 62, 48018 Faenza, Italy \\ 2 INRiM - Istituto Nazionale di Ricerca Metrologica, Strada delle Cacce 91, 10135 Torino, Italy \\ 3 ENEA, Agenzia Nazionale per le Nuove Tecnologie, l'Energia e lo Sviluppo Economico Sostenibile, UTTMATF, \\ Faenza Material Technologies Techn. Unit, Via Ravegnana 186, 48018 Faenza, Italy
}

Received: 17 March 2011 / Accepted: 17 June 2011

\begin{abstract}
The accuracy of thermal conductivity measurements is even more requested for materials characterization in energy-efficient buildings field. ENEA-UTTMATF and CertiMaC research group, as national institute and private laboratory respectively, cooperate in development of new measurement and analysis methods applied to buildings materials and their performances. For what concerns this kind of measurements, an Heat Flow-meter Transducer (HFT) is used. In order to give to both customers and other research institutes involved in the same field (e.g. International Comparison or International Round Robin Tests) the most exhaustive evaluation of the tested material thermal conductivity, a complete uncertainty analysis is implemented on the HFT measures. This uncertainty analysis, developed accordingly to the international standards and with the contribution of INRiM Institute, is described in this paper.
\end{abstract}

Keywords: Energy efficiency; building materials; heat flow meter; calibration; regression analysis; uncertainty budget; thermal conductivity.

\section{Introduction}

In this article, a brief description of the Unitherm ${ }^{\mathrm{TM}} 2022$ Heat Flow-meter Transducer (HFT) and an uncertainty analysis of its thermal conductivity measurements are reported (Refs. [1-3]). The analysis was performed taking into account the following three phases:

- calibration of the HFT by means of reference materials whose thermal properties are certified;

- construction of the HFT calibration curve by means of the Ordinary Least Squares method (OLS);

- use of the calibration curve to determine thermal conductivity of unknown materials under test.

The results, obtained by a collaboration among CertiMaC, ENEA-UTTMATF and INRiM, have to be considered as an important development to fully evaluate the uncertainty budget associated to thermal conductivity measurements performed by CertiMaC. This work has been developed in order to improve the metrological knowledge on thermal conductivity measurements for materials characterization in energy-efficient buildings field. In this application field such metrological characterisation is strongly requested by most recent European standards [4,5], even

^ Correspondence: l.laghi@certimac.it if actually it's not still implemented as a typical data analysis routine.

\section{Unitherm $^{\mathrm{TM}} 2022$ heat flow meter}

Thermal conductivity in the Unitherm ${ }^{\mathrm{TM}} 2022$ HFT (Figs. 1, 2) is measured by the guarded heat flow meter method (Refs. [1,2]). This test method covers a steadystate technique for the determination of the resistance to thermal transmission (thermal resistance) of materials whose specimen thicknesses is less than $25 \mathrm{~mm}$. A specimen and an HFT are sandwiched between two flat plates controlled at different temperatures to produce a heat flow through the test stack. The lower contact surface (with the sample) is part of a calibrated heat flux transducer. A reproducible load is applied to the test stack by a pneumatic cylinder, to ensure that there is a reproducible contact resistance between the specimen and plate surfaces. A guard surrounding the test stack is maintained at a uniform mean temperature of the two plates, in order to minimize lateral heat flow to and from the stack. Moreover, the guard is replaced by an insulating ring when the test mean temperature is under $20{ }^{\circ} \mathrm{C}$, in cryogenic conditions. As heat flows from the upper surface through the sample to the lower surface, an axial temperature gradient 

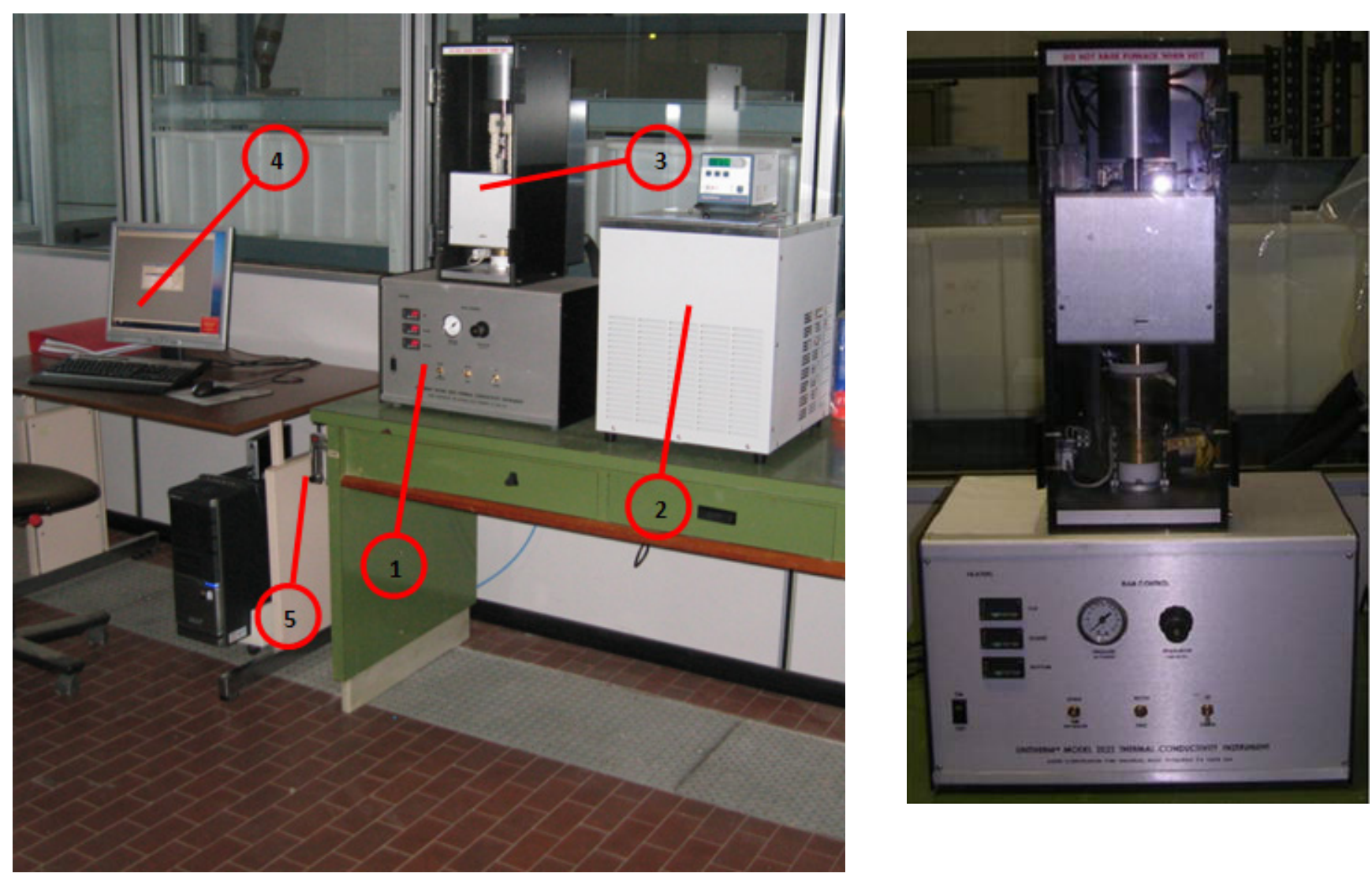

Fig. 1. (Color online) HFT laboratory at CertiMaC - ENEA, in Faenza. (1) Command and Control Panel in order to supervise the temperatures along the stack and the cylinder pressure. (2) Chiller with temperature automatic controller. (3) Stack section with HFT and Guard Heater. (4) Personal Computer with software and acquisition system. (5) Control and Command Panel for air and nitrogen system.

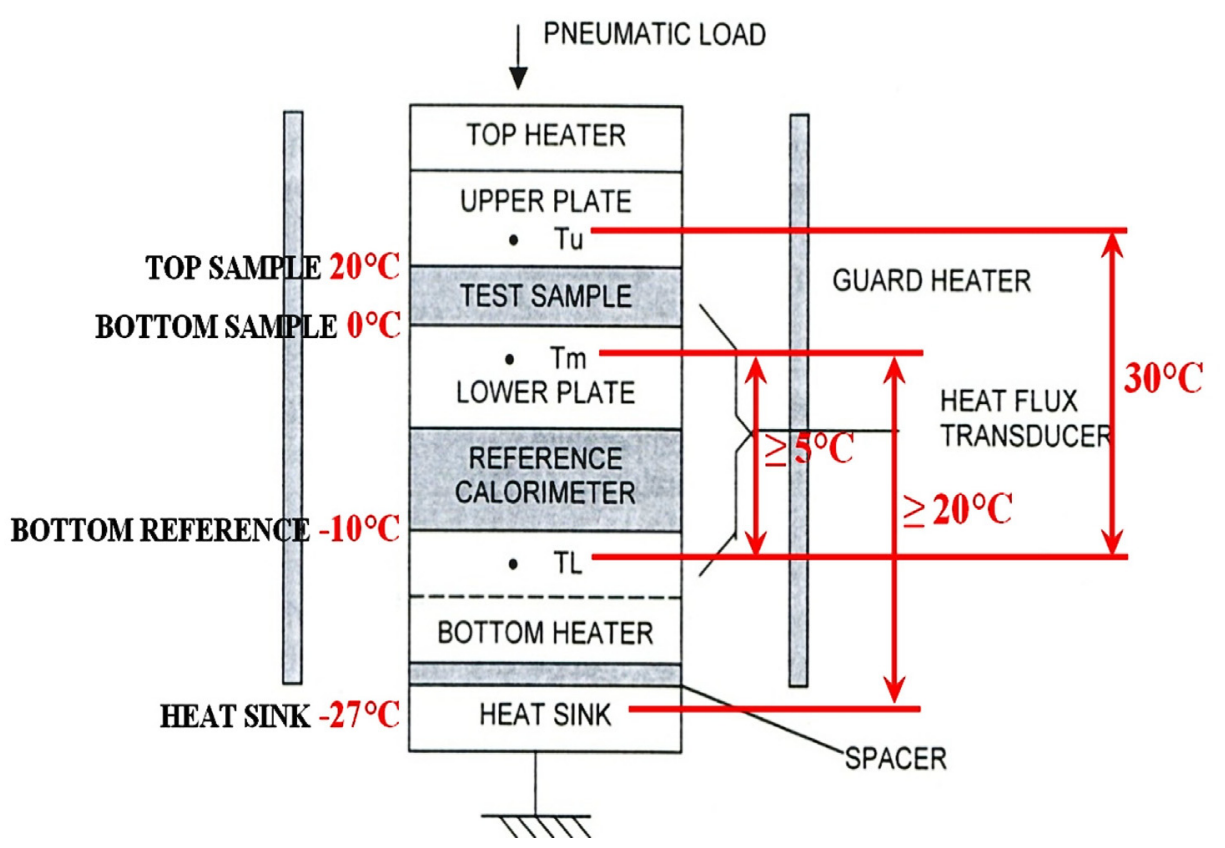

Fig. 2. (Color online) Test section schematic - temperature setting for $10{ }^{\circ} \mathrm{C}$ measurement. 
is established in the stack and at steady state, the difference in temperature between the surfaces contacting the specimen is measured with temperature sensors embedded in the surfaces, together with the electrical output of the HFT (Fig. 2).

This output (voltage) is proportional to the heat flow through the specimen, the HFT and the interfaces between the specimen and the apparatus. The proportionality is obtained through prior calibration of the system with six specimens of known and certificated thermal resistance measured under the same conditions, so that contact resistance at the surfaces is made reproducible.

At thermal equilibrium, the Fourier heat flow equation applied to the test sample becomes equation (1):

$$
R_{s}=\left[\left(T_{u}-T_{m}\right) / Q\right]-R_{\text {int }}
$$

where:

$R_{s}=$ thermal resistance of the test sample $\left(\mathrm{m}^{2} \mathrm{~K} / \mathrm{W}\right)$;

$T_{u}=$ upper plate surface temperature $\left({ }^{\circ} \mathrm{C}\right)$;

$T_{m}=$ lower plate surface temperature $\left({ }^{\circ} \mathrm{C}\right)$;

$Q=$ heat flux through the test sample $\left(\mathrm{W} / \mathrm{m}^{2}\right)$;

$R_{\text {int }}=$ total interface resistance between sample and surface plates $\left(\mathrm{m}^{2} \mathrm{~K} / \mathrm{W}\right)$.

The thermal resistance of the test sample is defined by equation (2):

$$
R_{s}=d / \lambda
$$

where:

$d=$ samples thickness $(\mathrm{m})$;

$\lambda=$ thermal conductivity $(\mathrm{W} /(\mathrm{m} \mathrm{K}))$.

The interface thermal resistance $R_{\text {int }}$ must be included in equation (1) because the HFT does not measure the actual temperature drop in the sample itself, but rather the temperature difference between the upper and lower surface plates in contact with the sample. The heat flux through the sample is measured with a transducer located just below the sample (HFT). The heat flux is determined by measuring the temperature difference across the reference calorimeter (see Eq. (3)):

$$
Q=N\left(T_{m}-T_{L}\right)
$$

where:

$N=$ reference calorimeter heat transfer coefficient $\left(\mathrm{W} /\left(\mathrm{m}^{2} \mathrm{~K}\right)\right)$;

$T_{m}=$ lower plate surface temperature $\left({ }^{\circ} \mathrm{C}\right)$;

$T_{L}=$ bottom heater temperature $\left({ }^{\circ} \mathrm{C}\right)$;

Combining equations (2) and (3) yields the following expression for the sample thermal resistance (Eqs. (4) and (5)):

$$
R_{s}=F\left[\left(T_{u}-T_{m}\right) /\left(T_{m}-T_{L}\right)\right]-R_{\text {int }}
$$

or

$$
R_{s}=F\left(\Delta T_{s} / \Delta T_{r}\right)-R_{i n t}=F T_{R A}-R_{i n t}
$$

where:

$F=$ proportionality constant $\left(\mathrm{m}^{2} \mathrm{~K} / \mathrm{W}\right)$;

$\Delta T_{s}=$ temperature difference across the sample $\left({ }^{\circ} \mathrm{C}\right)$;
$\Delta T_{r}=$ temperature difference across the reference calorimeter $\left({ }^{\circ} \mathrm{C}\right)$;

$T_{R A}=\Delta T_{s} / \Delta T_{r}\left({ }^{\circ} \mathrm{C} /{ }^{\circ} \mathrm{C}\right)$.

Under ideal conditions, when there is no heat loss or gain along the outer surface of the test stack, the factor $F$ is the inverse of the reference calorimeter heat transfer coefficient, $N$. Such conditions are closely approximated in the Model 2022 because the guard heater surrounding the test stack is actively controlled. Its temperature, comparable to the sample mean temperature, is controlled by means of thermocouples in order to avoid circumferential heat flow distortions and to guarantee a mono-dimensional flux.

To determine $F$ and $R_{\text {int }}$ in equation (5), the Model 2022 must be calibrated first. Equation (5) shows that there is a linear relationship between $R_{s}$ and $T_{R A}$ which can be estimated by means of a linear regression obtained with OLS Method. After the temperature ratios $T_{R A}$ are measured for several samples of known thermal resistance and the results are plotted on a graph, a straight line fitting the data points can be found (Fig. 3). The slope of the line is $F$ and the $y$-axis intersection is $R_{\text {int }}$.

These points represent the various calibration samples with certified thermal properties (by a producer by means of Technical Certificates) and thickness (see Eq. (2)): Vespel $6.35 \mathrm{~mm}$, Vespel $3.125 \mathrm{~mm}$ Vesple $9.525 \mathrm{~mm}$, Pirex 12.7 mm, Pirex 6.35 mm, Stainless Steel $19.05 \mathrm{~mm}$. This set is suitably chosen in order to sweep completely the thermal resistance range of the instrument, from $0.002 \mathrm{~m}^{2} \mathrm{~K} / \mathrm{W}$ to $0.02 \mathrm{~m}^{2} \mathrm{~K} / \mathrm{W}$.

Finally, although $R_{\text {int }}$ is accounted for in the analysis, it is important for obtaining high test accuracy that it is made as small as possible. This is achieved by using highly polished metal surfaces in contact with the sample, by clamping the sample with a reproducible force, and by applying heat transfer compound to the contacting surfaces.

The thermal conductivity determination of an unknown specimen shall only be conducted at a temperature within a range and under applied load conditions for which valid calibration data exist. Under the same conditions and after thermal equilibrium is attained, it is possible to measure $T_{R A}$ by calculating the mean temperature values on the sample and the reference material in a fixed temporal range (Ref. [1]). Moreover, it will be possible to estimate thermal resistance on the basis of the calibration linear fit (Fig. 4). Finally, thermal conductivity is estimated from thermal resistance value by measuring the sample thickness.

\section{Evaluation of the uncertainty budget associated to the heat flow meter}

A procedure to evaluate the uncertainties associated to the measures obtained from HFT is described (Refs. [3,6-10]).

In accordance with the metrological features described in previous paragraphs, the uncertainty budget is performed on the basis of the following steps. These are 


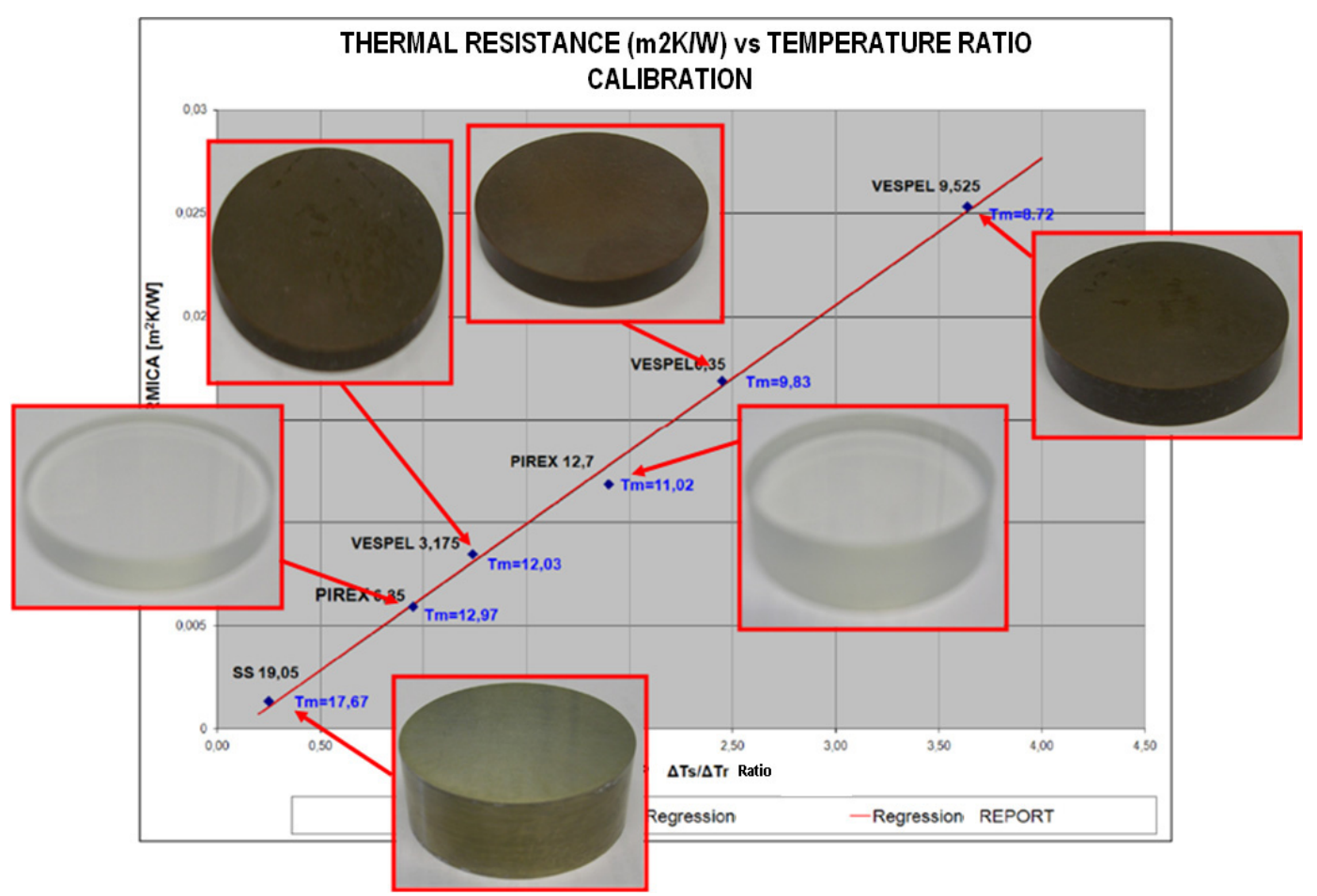

Fig. 3. (Color online) Straight line through the experimental points obtained during HFT calibration.

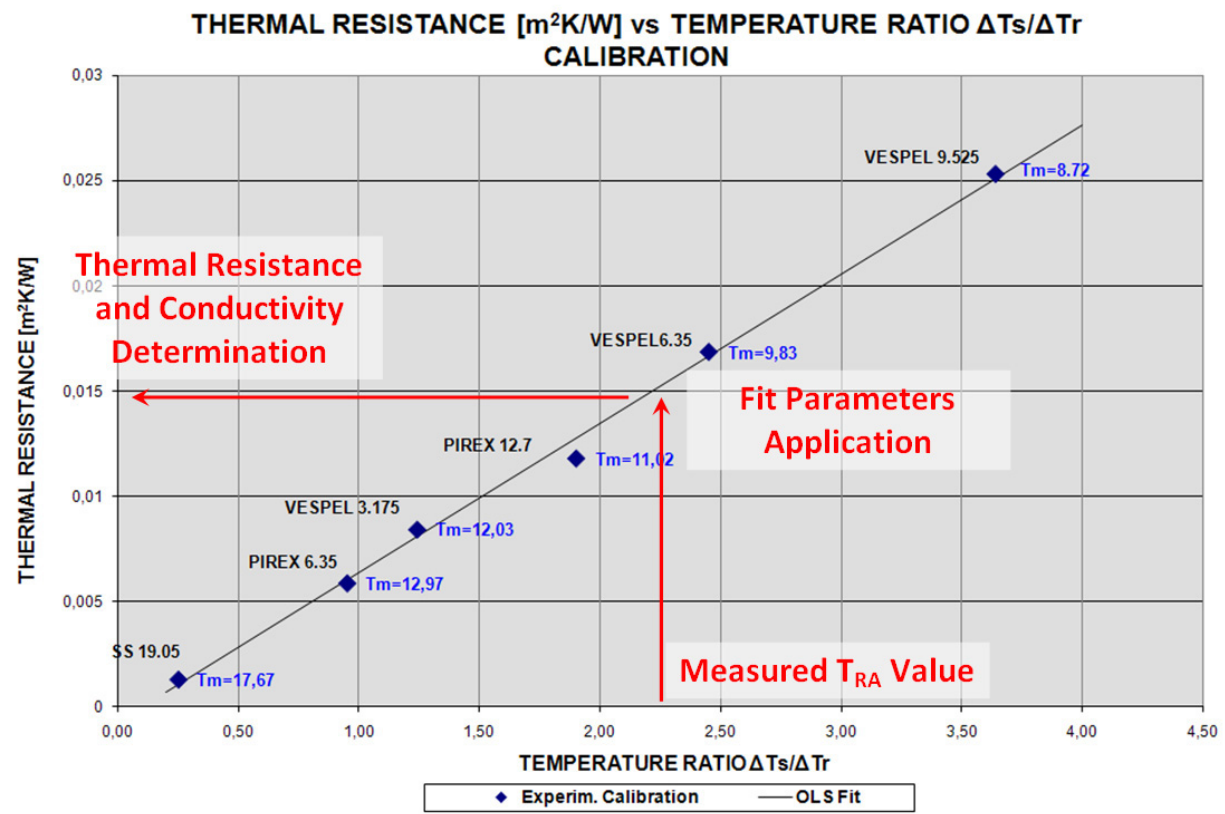

Fig. 4. (Color online) Thermal Conductivity determination for specimens of unknown thermal resistance.

demonstratively applied to a set of calibration data obtained for a characterization of the HFT performed during July 2008 (at a mean temperature of the reference sample of about $\left.10^{\circ} \mathrm{C}\right)$ :

(1) evaluation of the uncertainties associated to the six couples of values $\left(T_{R A}, R_{s}\right)$ related to the preliminary calibration of the HFT by means of the six reference materials;
(2) accordingly to the physical model at the basis of the HFT operation, adoption of a straight line as the model for fitting the calibration points: hence, estimation of both parameters $F$ and $R_{\text {int }}$ and evaluation of the associated uncertainties;

(3) uncertainty propagation to the thermal resistances of materials under test estimated by applying the calibration curve to the relevant $T_{R A}$ measures; 
Table 1. Uncertainty budget for one of the six reference materials: VESPEL QREF-962.

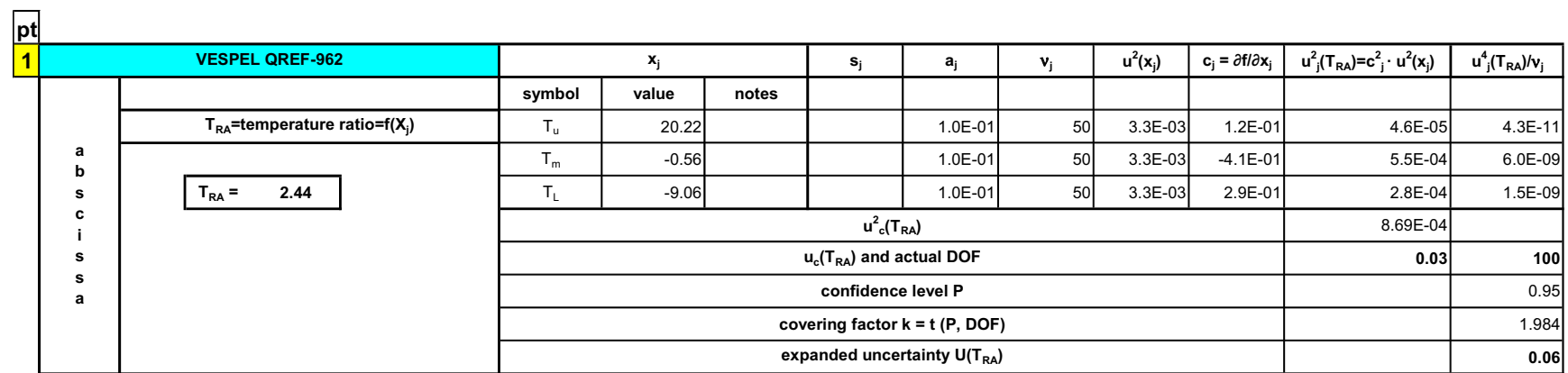

\begin{tabular}{|c|c|c|c|c|c|c|c|c|c|c|c|}
\hline & & \multicolumn{3}{|c|}{$\overline{x_{j}}$} & $s_{j}$ & $a_{j}$ & $v_{j}$ & $u^{2}\left(x_{j}\right)$ & $c_{j}=\partial f / \partial x_{j}$ & $u_{j}^{2}\left(R_{s}\right)=c_{j}^{2} \cdot u^{2}\left(x_{j}\right)$ & $\mathrm{u}_{\mathrm{j}}^{4}\left(\mathbf{R}_{\mathrm{s}}\right) / \mathrm{v}_{\mathrm{j}}$ \\
\hline \multirow[b]{3}{*}{0} & & symbol & value & notes & & & & & & & \\
\hline & $R_{S}=$ thermal resistance $=f\left(X_{j}\right)$ & \multirow{2}{*}{ d } & \multirow{2}{*}{0.00635} & reproducibility & $2.0 \mathrm{E}-05$ & & 9 & $4.0 \mathrm{E}-10$ & $2.7 \mathrm{E}+00$ & $2.8 \mathrm{E}-09$ & $8.7 \mathrm{E}-19$ \\
\hline & \multirow{7}{*}{$R_{S}=\quad 0.01689$} & & & resolution & & $1.0 \mathrm{E}-05$ & 50 & $3.3 \mathrm{E}-11$ & $2.7 \mathrm{E}+00$ & $2.4 \mathrm{E}-10$ & $1.1 \mathrm{E}-21$ \\
\hline d & & $\lambda$ & 0.376 & & & $9.0 \mathrm{E}-03$ & 50 & $2.7 \mathrm{E}-05$ & $-4.5 \mathrm{E}-02$ & $5.5 \mathrm{E}-08$ & $6.0 \mathrm{E}-17$ \\
\hline $\begin{array}{l}\mathrm{i} \\
\mathrm{n}\end{array}$ & & \multicolumn{8}{|c|}{$u_{c}^{2}\left(R_{s}\right)$} & $5.8 \mathrm{E}-08$ & \\
\hline a & & \multicolumn{8}{|c|}{$u_{c}\left(R_{s}\right)$ and actual DOF } & 0.00024 & 55 \\
\hline e & & \multicolumn{8}{|c|}{ confidence level $P$} & & 0.95 \\
\hline & & \multicolumn{8}{|c|}{ covering factor $k=t(P, D O F)$} & & 2.005 \\
\hline & & \multicolumn{8}{|c|}{ expanded uncertainty $\mathrm{U}\left(R_{\mathrm{s}}\right)$} & & 0.00048 \\
\hline
\end{tabular}

(4) final evaluation of both thermal conductivity of the tested materials and the associated standard and expanded uncertainty.

\subsection{Calibration: uncertainties associated to reference data}

Six samples of reference materials are used to build a calibration straight line associated to the HFT, accordingly to equation (5). For each sample, $R_{s}$ is well-known and the values of $T_{R A}$ are measured. The evaluation of the combined uncertainty associated to both $T_{R A}$ and $R_{s}$ is performed following the scheme illustrated in Table 1, where data referring to the reference material VESPEL QREF962 are reported as an example. Table 1 is a useful way to express the whole uncertainty budget of a physical quantity, aimed to give evidence to each single contribution. It should be underlined here that the measurement units of the various physical quantities are not reported in the table, to facilitate its reading. The measurement results are expressed using the same multiple or sub-multiple, and the adopted mathematical model is correct for what concerns the dimensional analysis, so that the values reported are guaranteed to be homogeneous and dimensionally correct.

The symbols in Table 1 have the following meanings:

- column $x_{j}$ : symbol, value and note related to the $j$ th independent input variable;

- column $s_{j}$ : standard uncertainty related to type A contributions (estimates of the standard deviation $\sigma_{j}$ ). For what concerns temperatures, at the moment it is not possible to acquire a statistical sample of repeated measurements in conditions of thermal equilibrium: the instrument in fact acquires the temperature values and gives their mean values when the steady state is attained. For what concerns the thickness $d$ of the sample, the value $s$ is calculated from a set of ten repeated measurements;

- column $a_{j}$ : semi-amplitude of the variability range, from which the appropriate type B uncertainty contributions are calculated. For what concerns temperatures, a variability range of $0.2{ }^{\circ} \mathrm{C}$ is considered reasonable on the basis of the knowledge of both the adopted transducers (type $\mathrm{K}$ thermocouples) and the HFT itself: temperature values are considered to be uniformly distributed in this range (rectangular distribution). For what concerns $d$ and $\lambda, a_{j}$ values are determinated by considering the instrument resolution (a caliper) and the data sheet information, respectively;

- column $\nu_{j}$ : degrees of freedom (DOF) associated to the corresponding uncertainty contribution (the value of 50 DOF is used when the quality of the information is considered "very funded");

- column $u^{2}\left(x_{j}\right)$ : variances of the independent variables;

- column $c_{j}$ : sensitivity coefficients obtained from the mathematical models by which $T_{R A}$ and $R_{s}$ are expressed in terms of the input variables;

- column $u_{j}^{2}\left(T_{R A}\right.$ or $\left.R_{s}\right)=c_{j}^{2} u^{2}\left(x_{j}\right)$ : contributions to the variance of $T_{R A}$ or $R_{s}$ due to the different considered independent variables;

- column $u_{j}^{4}\left(T_{R A}\right.$ or $\left.R_{s}\right) / \nu_{j}: j$ th contributions in the Welch-Satterthwaite formula, used to estimate the actual DOF;

- $u_{c}^{2}\left(T_{R A}\right.$ or $\left.R_{s}\right)$ : combined variance of $T_{R A}$ or $R_{s}$, calculated as $\Sigma u_{j}^{2}\left(T_{R A}\right.$ or $\left.R_{s}\right)$;

- $u_{c}\left(T_{R A}\right.$ or $\left.R_{s}\right)$ : standard uncertainty of $T_{R A}$ or $R_{s}$, calculated as the square root of $u_{c}^{2}\left(T_{R A}\right.$ or $\left.R_{s}\right)$;

- actual DOF for $T_{R A}$ or $R_{s}$, calculated by applying the Welch-Satterthwaite formula;

- coverage factor $k$, calculated by the Student's $t$-distribution on the basis of both the chosen confidence level and the actual DOF; 
Table 2. Synthesis of the calibration data obtained in correspondence to the reference materials.

\begin{tabular}{|l|c|r|r|r|r|r|r|r|r|}
\hline \multicolumn{1}{|c|}{ sample } & \multicolumn{1}{c|}{$\begin{array}{c}\mathbf{d} \\
{[\mathbf{m}]}\end{array}$} & $\begin{array}{c}\mathbf{T}_{\mathbf{R A}} \\
{\left[{ }^{\circ} \mathbf{C} /{ }^{\circ} \mathbf{C}\right]}\end{array}$ & $\begin{array}{c}\mathbf{u}\left(\mathbf{T}_{\mathrm{RA}}\right) \\
{\left[{ }^{\circ} \mathbf{C} /{ }^{\circ} \mathbf{C}\right]}\end{array}$ & \multicolumn{1}{c|}{$\begin{array}{c}\mathbf{u}\left(\mathbf{T}_{\mathrm{RA}}\right) \\
{[\%]}\end{array}$} & $\begin{array}{c}\mathbf{U}\left(\mathbf{T}_{\mathrm{RA}}\right) \\
{\left[{ }^{\circ} \mathbf{C} /{ }^{\circ} \mathbf{C}\right]}\end{array}$ & $\begin{array}{c}\mathbf{R}_{\mathbf{s}} \\
{\left[\mathbf{m}^{2} \mathbf{K} / \mathbf{W}\right]}\end{array}$ & $\begin{array}{c}\mathbf{u}\left(\mathbf{R}_{\mathbf{s}}\right) \\
{\left[\mathbf{m}^{2} \mathbf{K} / \mathbf{W}\right]}\end{array}$ & $\begin{array}{c}\mathbf{u}\left(\mathbf{R}_{\mathbf{s}}\right) \\
{[\%]}\end{array}$ & $\begin{array}{c}\mathbf{U}\left(\mathbf{R}_{\mathbf{s}}\right) \\
{\left[\mathbf{m}^{2} \mathbf{K} / \mathbf{W}\right]}\end{array}$ \\
\hline SS QREF-941 & 0.01905 & 0.255 & 0.004 & 1.7 & 0.01 & 0.0013 & $1.5 \mathrm{E}-06$ & 0.1 & $3.3 \mathrm{E}-06$ \\
\hline PIREX QREF-952 & 0.00635 & 0.946 & 0.009 & 1.0 & 0.02 & 0.0059 & $3.4 \mathrm{E}-05$ & 0.6 & $6.9 \mathrm{E}-05$ \\
\hline VESPEL QREF-963 & 0.00318 & 1.239 & 0.012 & 1.0 & 0.02 & 0.0084 & $1.3 \mathrm{E}-04$ & 1.5 & $2.6 \mathrm{E}-04$ \\
\hline PIREX QREF-951 & 0.01270 & 1.901 & 0.021 & 1.1 & 0.04 & 0.0118 & $6.1 \mathrm{E}-05$ & 0.5 & $1.2 \mathrm{E}-04$ \\
\hline VESPEL QREF-962 & 0.00635 & 2.445 & 0.029 & 1.2 & 0.06 & 0.0169 & $2.4 \mathrm{E}-04$ & 1.4 & $4.8 \mathrm{E}-04$ \\
\hline VESPEL QREF-969 & 0.00953 & 3.640 & 0.056 & 1.5 & 0.11 & 0.0253 & $3.6 \mathrm{E}-04$ & 1.4 & \\
\hline
\end{tabular}

- expanded uncertainty: calculated as the product between $k$ and $u_{c}\left(T_{R A}\right.$ or $\left.R_{s}\right)$.

A synthesis of the calibration data obtained in correspondence to the reference materials is reported in Table 2.

\subsection{Statistical method used to estimate the calibration curve of the heat flow meter}

The six couples of values $\left(T_{R A}, R_{s}\right)$, obtained during the calibration phase by means of the reference materials, have been plotted on a corresponding $x-y$ graph. In order to determine a straight line fitting the data points, the slope $F$ of the line and the $y$-axis intercept $R_{\text {int }}$ have to be estimated (see Sect. 2). It is here necessary to make the following considerations:

- as described in the previous paragraph, the calibration points in the $x-y$ graph are characterized by uncertainties on both the abscissa and ordinate, that are comparable in relative terms. The statistical method that should be formally used to fit this data set is known as the Total Least Square (TLS) method. Generally, HFT metrology commonly uses OLS method, so the adoption of TLS method in treating this type of calibration curve is something relatively "new". Therefore, some further analysis and considerations will be taken into consideration before validating its adoption;

- in the following, OLS will be implemented to fit the calibration data accordingly to the linear model (Fourier's Law). It should be considered that this method needs to be applied under the hypothesis that all the experimental points have no uncertainties on abscissa and equal uncertainties on ordinate; it is obvious that both these hypothesis are not appropriate to describe the experimental situation under test here. In spite of this fact, OLS method is applied in order to guarantee the continuity with the previous way of data elaboration. The novelty in this approach, in comparison with the usual approach implemented up to now, can be summarized in these two points:

(1) the goodness of the method was tested and proved at the desired confidence level, taking into consideration in a proper way the expanded uncertainties of the experimental points determined in Sect. 3.1, Table 2;
(2) the covariance of the estimated parameters (slope $F$ and intercept $R_{\text {int }}$, respectively) was calculated and considered in the subsequent uncertainty propagation on the values of thermal resistance of unknown materials.

The calculations were performed by applying the formulas reported in reference [3] and checked by comparison versus the statistical tool provided by Excel. The term $s\left(F, R_{\text {int }}\right)$ indicates the covariance between the statistical estimates. The goodness of the OLS method in fitting the experimental data was verified by building around the regression line the uncertainty bands at the confidence level of $95 \%$, and checking if they overlap the expanded uncertainties of the experimental values. The confidence bands were estimated by combining in a proper way the uncertainties of both slope and intercept, and taking into account the actual DOF (by which the appropriate coverage factor was calculated). The results can be seen in the graph reported in Figure 5. It can be concluded that there is a reasonable accordance between the OLS fit and the expanded uncertainties of the calibration data: that justifies the use of OLS method as the fitting standard method in this type of applications.

\subsection{Measurement of thermal resistance of unknown materials}

Now, using the calibration curve of the HFT, it will be possible to estimate the thermal resistance of unknown materials. The procedure can be divided in the following two steps (see Sect. 2):

(1) measurement of $T_{R A}$, and evaluation of its associated combined uncertainty $u\left(T_{R A}\right)$ and DOF, for the material under test;

(2) use of the parameter $F$ and $R_{\text {int }}$ to estimate the thermal resistance $R_{s}$ of the material under test; the associated combined uncertainty $u\left(R_{s}\right)$ is calculated propagating the contributions due to all the involved variables $\left(T_{R A}, F\right.$ and $R_{\text {int }}$ with their standard uncertainties and covariances).

As an example, this procedure was applied to experimental measures of $T_{R A}$ obtained during the thermal characterization of four different materials (Tab. 3). The obtained results, related to one of considered materials, are 




Fig. 5. (Color online) Fit of the calibration data by OLS method and construction of the confidence bands.

Table 3. Synthesis of thermal resistances, and associated uncertainties, determined for different materials by using the regression parameters estimated by OLS.

\begin{tabular}{|c|c|c|c|c|c|c|c|}
\hline \multicolumn{2}{|c|}{ label CertiMaC } & $T_{R A}$ & $\mathrm{u}\left(\mathrm{T}_{\mathrm{RA}}\right)$ & $\mathbf{R}_{\mathrm{s}}$ & $\mathbf{u}\left(\mathbf{R}_{\mathrm{s}}\right)$ & $U\left(T_{R A}\right)$ & $\mathrm{U}\left(\mathbf{R}_{\mathrm{s}}\right)$ \\
\hline $\mathrm{P} 1$ - B & exp. point. 1 & 0.76 & 0.01 & $4.65 \mathrm{E}-03$ & $3.1 \mathrm{E}-04$ & $1.5 \mathrm{E}-02$ & $8.5 \mathrm{E}-04$ \\
\hline CLT0376 & exp. point. 2 & 1.81 & 0.02 & 1.21E-02 & $2.6 \mathrm{E}-04$ & $3.8 \mathrm{E}-02$ & $6.2 \mathrm{E}-04$ \\
\hline СМТ0379 & exp. point. 3 & 3.09 & 0.04 & 2.12E-02 & $4.6 \mathrm{E}-04$ & 8.3E-02 & $1.0 \mathrm{E}-03$ \\
\hline СМт0396 & exp. point. 4 & 4.14 & 0.07 & 2.87E-02 & $7.2 \mathrm{E}-04$ & $1.3 \mathrm{E}-01$ & 1.6E-03 \\
\hline
\end{tabular}

reported in Tables 4 and 5, respectively. The tables are based on the same uncertainty analysis described in Section 3.1. A synthesis of the obtained results is reported in Figure 6.

\subsection{Measurement of thermal conductivity of unknown materials}

The final step consists in the determination of the thermal conductivity of the tested materials, by applying equation (2) and the usual rules for the uncertainty propagation. As an example, the values of $\lambda$ were calculated for the experimental data considered in Section 3.3. The example takes into consideration a measurement at $10^{\circ} \mathrm{C}$ in dry state, that represents a reference condition for analysis on building materials (Fig. 2 - temperature setting) as requested from European standards [4,5]. Moreover, the operative temperature span is related to the sample mean temperature in the instrument range from $0{ }^{\circ} \mathrm{C}$ to $300{ }^{\circ} \mathrm{C}$. In this specific case, for analysis at $10^{\circ} \mathrm{C}$ on building materials, $T_{u}$ and $T_{m}$ are controlled at about $20^{\circ} \mathrm{C}$ and $0{ }^{\circ} \mathrm{C}$ respectively, in accordance with the instrument specification (Fig. 2).

\subsection{Uncertainty analysis implemented on a customized LabVIEW executable}

The whole uncertainty analysis was implemented in a proper executable by means of LabVIEW software. Some 


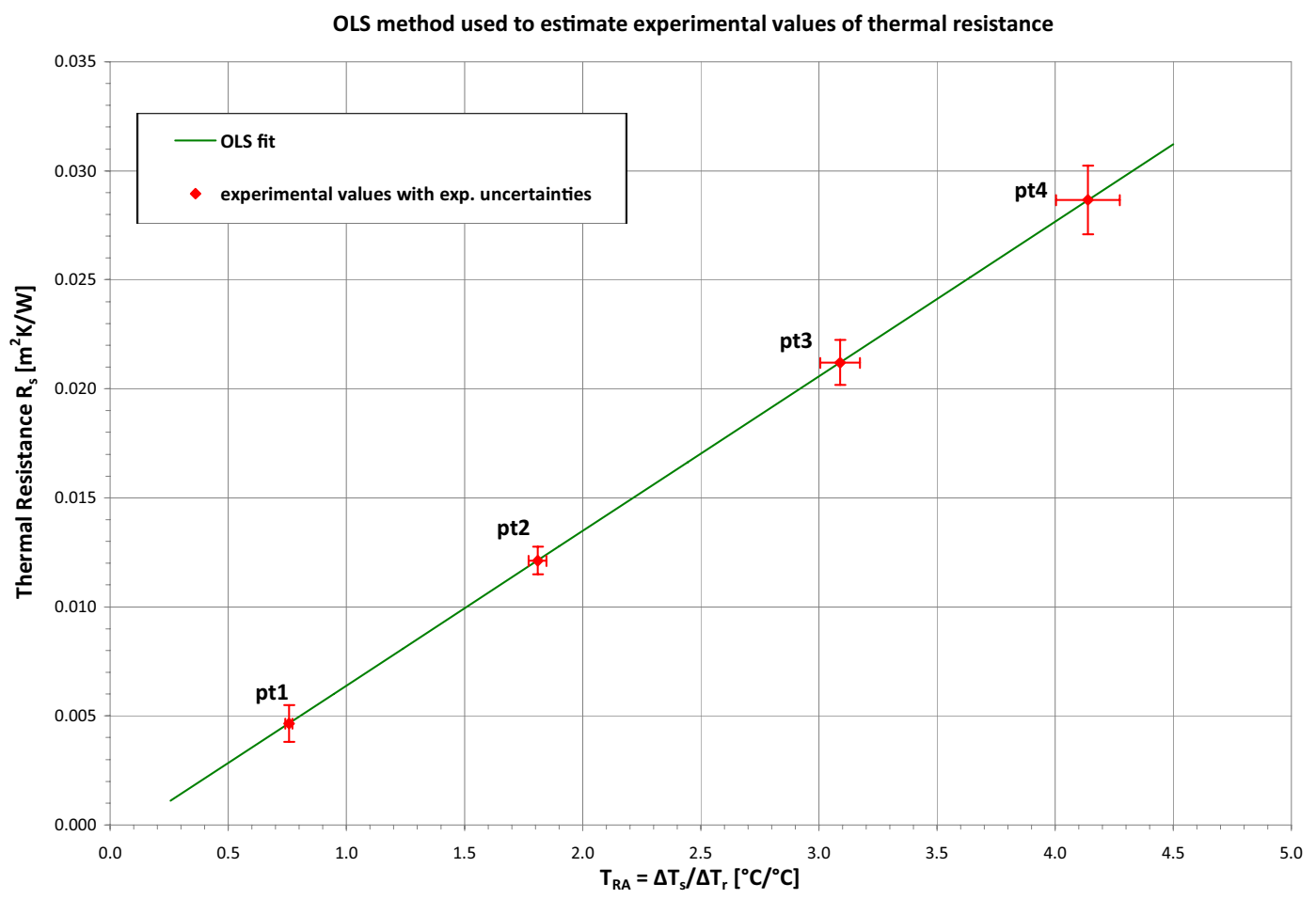

Fig. 6. (Color online) Thermal resistances determined by applying OLS method.

Table 4. Measures of $T_{R A}$ and $R_{s}$, and associated combined uncertainties $u\left(T_{R A}\right), u\left(R_{s}\right)$ and DOF, for materials under test.

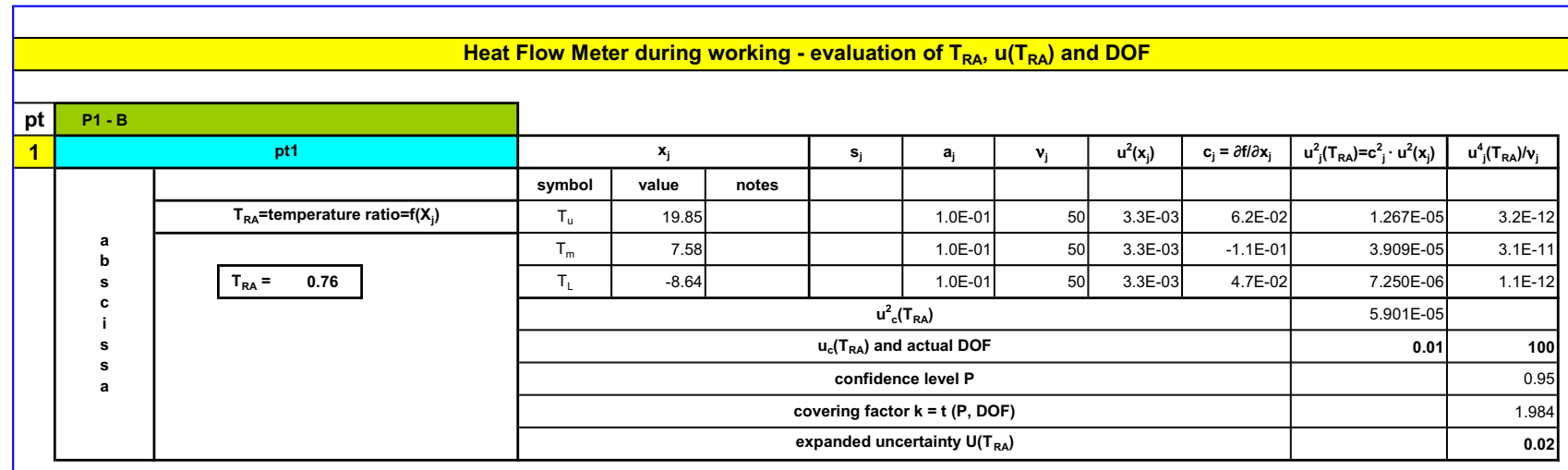

\begin{tabular}{|c|c|c|c|c|c|c|c|c|c|c|c|c|}
\hline \multicolumn{13}{|c|}{ Heat Flow Meter during working - evaluation of $R_{s}, u\left(R_{s}\right)$ and DOF } \\
\hline pt & \multicolumn{12}{|c|}{$\begin{array}{ll}\mathrm{P} 1-\mathrm{B} \\
\end{array}$} \\
\hline 1 & \multicolumn{2}{|r|}{$\overline{p t 1}$} & \multicolumn{3}{|c|}{$x_{j}$} & $s_{j}$ & $a_{j}$ & $v_{j}$ & $u^{2}\left(x_{j}\right)$ & $c_{i}=\partial f / \partial x_{j}$ & $u_{j}^{2}\left(R_{s}\right)=c_{j}^{2} \cdot u^{2}\left(x_{j}\right)$ & $u_{j}^{4}\left(R_{s}\right) / v_{j}$ \\
\hline & \multirow{11}{*}{$\begin{array}{l}0 \\
\mathrm{r} \\
\mathrm{d} \\
\mathrm{i} \\
\mathrm{n} \\
\mathrm{a} \\
\mathrm{t} \\
\mathrm{e}\end{array}$} & & symbol & value & notes & & & & & & & \\
\hline & & $\mathrm{R}_{\mathrm{S}}=$ thermal resistance $=\mathrm{f}\left(\mathrm{X}_{\mathrm{j}}\right)$ & $\mathrm{F}$ & $7.096 \mathrm{E}-03$ & from OLS & $2.0 E-04$ & & & $4.2 \mathrm{E}-08$ & $0.0 E+00$ & $0.000 \mathrm{E}+00$ & \\
\hline & & & $R_{\text {int }}$ & $-7.134 \mathrm{E}-04$ & from OLS & $4.2 E-04$ & & & $1.8 \mathrm{E}-07$ & $1.0 E+00$ & $1.768 \mathrm{E}-07$ & \\
\hline & & & $\mathrm{s}\left(\mathrm{F}, R_{\mathrm{int}}\right)$ & & from OLS & $-7.3 \mathrm{E}-08$ & & & $-7.3 \mathrm{E}-08$ & $0.0 E+00$ & $0.000 \mathrm{E}+00$ & \\
\hline & & & & & & & & 4 & & & $1.768 \mathrm{E}-07$ & $7.8 \mathrm{E}-15$ \\
\hline & & $R_{S}=-7.13 E-04$ & $T_{R A}$ & $0.000 \mathrm{E}+00$ & measurement & $0.0 E+00$ & & 100 & $0.0 E+00$ & $7.1 \mathrm{E}-03$ & $0.000 E+00$ & $0.0 E+00$ \\
\hline & & & \multicolumn{8}{|c|}{$u_{c}^{2}\left(R_{s}\right)$} & $1.768 \mathrm{E}-07$ & \\
\hline & & & \multicolumn{8}{|c|}{$\mathrm{u}_{\mathrm{c}}\left(\mathrm{R}_{\mathrm{S}}\right)$ and actual DOF } & $4.2 \mathrm{E}-04$ & 4 \\
\hline & & & \multicolumn{8}{|c|}{ confidence level P } & & 0.95 \\
\hline & & & \multicolumn{8}{|c|}{ covering factor $k=t(P, D O F)$} & & 2.776 \\
\hline & & & \multicolumn{8}{|c|}{ expanded uncertainty $\mathrm{U}\left(\mathrm{R}_{\mathrm{s}}\right)$} & & $1.2 \mathrm{E}-03$ \\
\hline
\end{tabular}




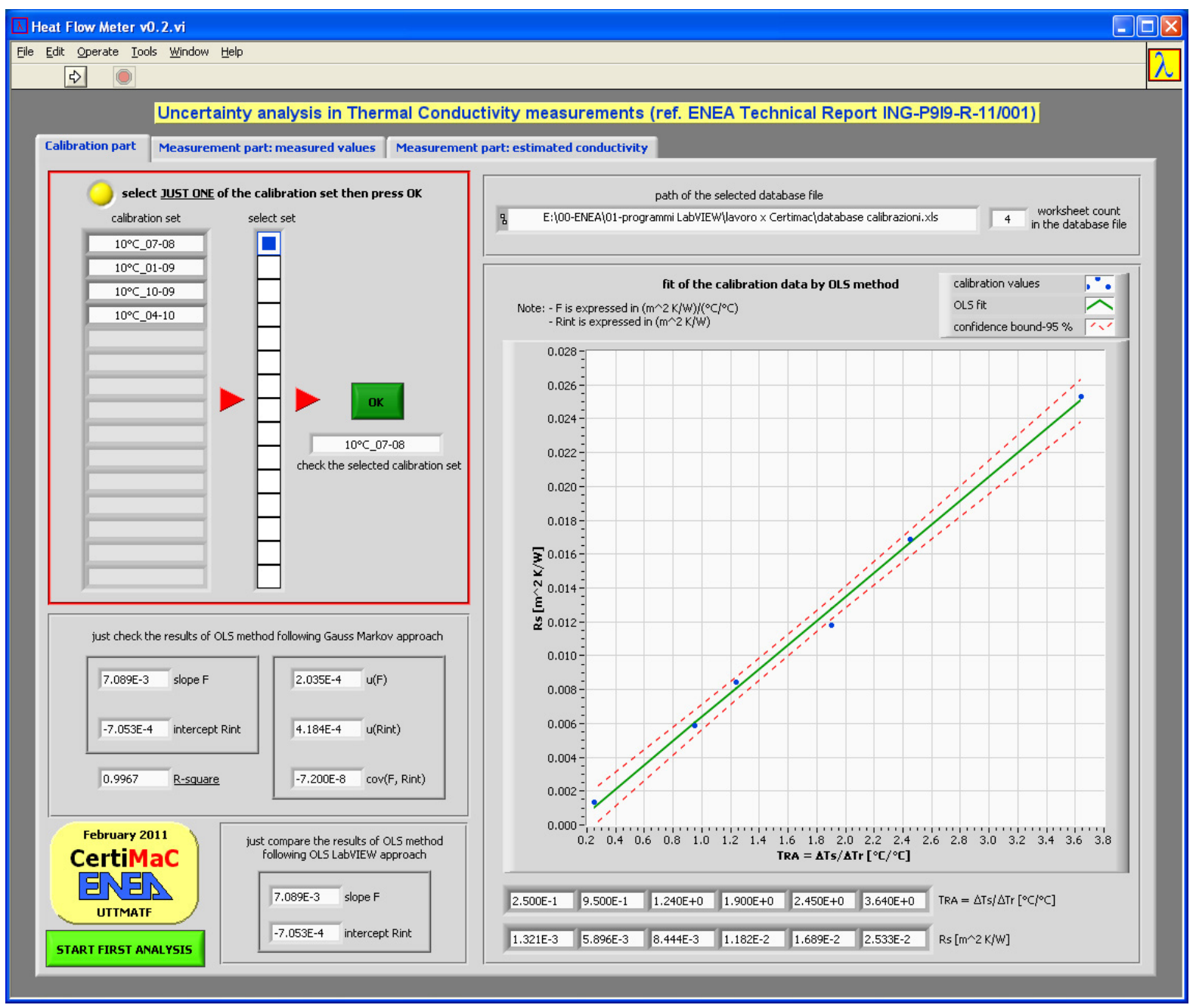

Fig. 7. (Color online) Software Snapshot - Sheet 1: calibration part.

snapshots of the software execution are reported in Figures 7-9.

\section{Discussion}

A complete metrological characterisation of thermal conductivity measurements requests a deep analysis of the various uncertainty experimental contributes in order to give an even more accurate technical support to all building materials manufacturers involved in energy efficiency and thermal insulation field. For these reasons a statistical method has been implemented to obtain a proper characterisation of building materials in terms of their thermal conductivity uncertainty. Moreover, this uncertainty analysis has confirmed that OLS method can be considered as reasonably appropriate to fit the calibration data for HFT measurements of thermal conductivity. Finally, this analysis has allowed to accurately evaluate the uncertainties associated to the main physical quantities involved in this experimental process.

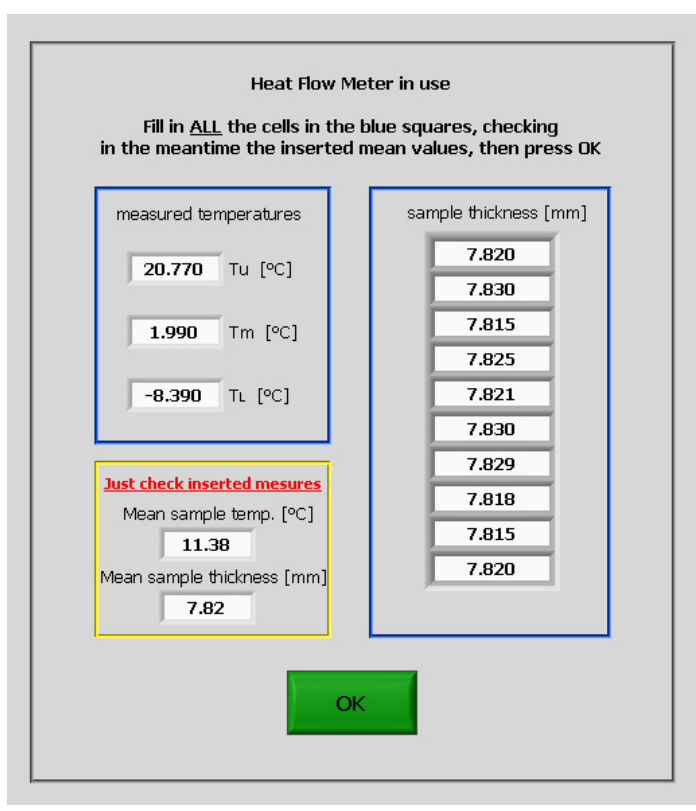

Fig. 8. (Color online) Software Snapshot - Sheet 2: measured values. 


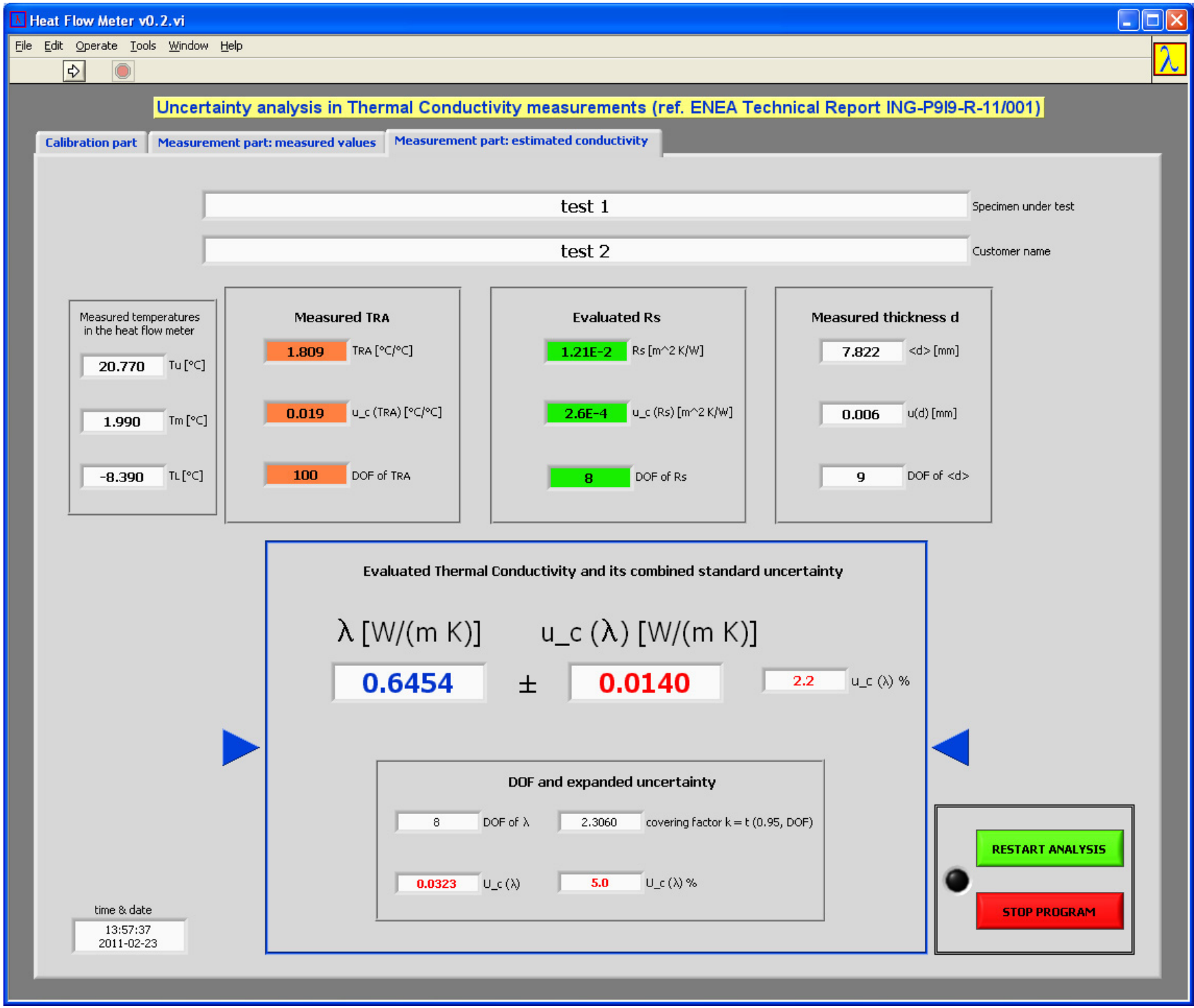

Fig. 9. (Color online) Software Snapshot - Sheet 2: estimated conductivity.

Table 5. Final results of $\lambda$ with their associated combined uncertainties and DOF.

\begin{tabular}{|c|c|c|c|c|c|c|c|c|c|c|c|c|}
\hline \multicolumn{13}{|c|}{ Heat Flow Meter during working - evaluation of $\lambda, u(\lambda)$ and DOF } \\
\hline pt & \multicolumn{12}{|c|}{ P1-B } \\
\hline \multirow[t]{10}{*}{1} & \multicolumn{2}{|r|}{ pt1 } & \multicolumn{3}{|c|}{$x_{j}$} & $s_{j}$ & $a_{\mathrm{i}}$ & $v_{j}$ & $u^{2}\left(x_{j}\right)$ & $c_{j}=\partial f / \partial x_{j}$ & $u_{j}^{2}(\lambda)=c_{j}^{2} \cdot u^{2}\left(x_{j}\right)$ & $u_{j}^{4}(\lambda) / v_{j}$ \\
\hline & \multirow{2}{*}{\multicolumn{2}{|c|}{$\lambda=$ thermal conductivity $=f\left(X_{j}\right)$}} & symbol & value & notes & & & & & & & \\
\hline & & & d & $1.72 \mathrm{E}-03$ & & $5.8 \mathrm{E}-05$ & & 9 & $3.3 \mathrm{E}-09$ & $2.1 \mathrm{E}+02$ & $1.538 \mathrm{E}-04$ & $2.6 \mathrm{E}-09$ \\
\hline & & \multirow{7}{*}{$\lambda=\quad 0.370$} & $R_{\mathrm{s}}$ & \begin{tabular}{ll|}
$4.65 \mathrm{E}-03$ \\
\end{tabular} & & $3.1 \mathrm{E}-04$ & & 4 & $9.4 \mathrm{E}-08$ & $-7.9 E+01$ & $5.902 \mathrm{E}-04$ & $8.2 \mathrm{E}-08$ \\
\hline & & & & & & & & & & & & \\
\hline & & & \multicolumn{8}{|c|}{$u_{c}^{2}(\lambda)$} & $7.441 \mathrm{E}-04$ & \\
\hline & & & \multicolumn{8}{|c|}{$\mathrm{u}_{\mathrm{c}}(\lambda)$ and actual DOF } & 0.027 & 7 \\
\hline & & & \multirow{2}{*}{\multicolumn{8}{|c|}{ confidence level $P$}} & & 0.95 \\
\hline & & & \multirow{2}{*}{\multicolumn{8}{|c|}{ covering factor $k=t(P, D O F)$}} & & 2.447 \\
\hline & & & & & & & & & & & & 0.07 \\
\hline
\end{tabular}


Acknowledgements. The authors wish to remember Prof Gabriele Brondino (Politecnico di Torino): he was a skilful colleague and a good friend.

\section{References}

1. UnithermTM 2022 Heat Flow Meter Software \& Operation Manual

2. ASTM E1530-2004, Standard Test Method for Evaluating the Resistance to Thermal Transmission of Materials by the Guarded Heat Flow Meter Technique

3. Evaluation of measurement data, Guide to the expression of uncertainty in measurement JCGM 100:2008 (http:// www.bipm.org/utils/common/documents/jcgm/JCGM_ 100_2008_E.pdf)

4. EN 12664:2002, Thermal performance of building materials and products, Determination of thermal resistance by means of guarded hot plate and heat flow meter methods, Dry and moist products of medium and low thermal resistance
5. EN 12667:2002, Thermal performance of building materials and products, Determination of thermal resistance by means of guarded hot plate and heat flow meter methods, Products of high and medium thermal resistance

6. Misurare per decidere, Misure e statistica di base, edited by G. Barbato (Società Editrice Esculapio s.r.l., Bologna, Italy, 2002)

7. Statistica e probabilità per ingegneri, edited by G. Vicario, R. Levi (Società Editrice Esculapio s.r.l. Bologna, Italy, 2001)

8. Applied Regression Analysis, edited by N.R. Draper, H. Smith (John Wiley \& Sons, Inc., New York, London, Sydney, 1966)

9. A. Balsamo, G. Mana, F. Pennecchi, On the best fit of a line to uncertain observation pairs, Metrologia 42, 376-382 (2005)

10. M.J.T. Milton, P.M. Harris, I.M. Smith, A.S. Brown, B.A. Goody, Implementation of a generalized least-squares method for determining calibration curves from data with general uncertainty structures, Metrologia 43, S291-S298 (2006) 